Check for updates

1 Glasgow, UK

2 The BMJ, London, UK

3 Northern Deanery, UK

4 Kent, Sussex, and Surrey Deanery, UK

Correspondence to: G McLachlan Greta.mclachlan@nhs.net Cite this as: BMJ 2021;373:n998 http://dx.doi.org/10.1136/bmj.n998 Published: 20 April 2021

\section{Sexism, racism, and homophobia at the Royal College of Surgeons of England}

\author{
The diversity report is just the first step; the hard work starts now
}

Rahee Mapara, ${ }^{1}$ Clara Munro, ${ }^{2}$ Mobolaji Ajekigbe, ${ }^{3}$ Greta McLachlan ${ }^{4}$

On 18 March 2021, the Royal College of Surgeons of England published an independent review into its diversity and inclusion, led by Helena Kennedy, QC. The review was commissioned by Neil Mortensen as one of his first acts as president. The report concludes that "the college was not demonstrating itself to be a diverse and inclusive institution, reflecting the society in which we live or the changing profession of surgery.” Evidence was collated from 22 witnesses, an additional 75 participants, and a survey of 28000 college members with over 1400 responses. ${ }^{1}$ Some of the findings, while shocking, were sadly not surprising for many surgeons.

Personal evidence included a surgeon from the Middle East being welcomed as the "departmental terrorist," "jokes" being made about rape and sexual assault, and an applicant turned down for a job because, "I don't want a gay in the department." One gay black surgeon even felt unsafe giving evidence to the panel and spoke of feeling "real loneliness" while a trainee.

Among respondents to the survey, two thirds of those from a black ethnic background thought that the college was not representative of people like them. Only 6\% believed the college used its influence, resources, and assets effectively to combat discrimination, and three quarters believed the college did not do enough to foster an inclusive environment.

The report's criticism of the college as an "old boys' club" is symptomatic of a wider problem in UK medicine, where there are still pockets reminiscent of the "masonic and colonial." ${ }^{1}$ The Romney report in 2019, for example, identified sexism, sexual harassment, and an old boys' club culture within the $\mathrm{BMA},{ }^{23}$ the largest trade union representing doctors in the UK.

\section{Selection processes}

Kennedy's report focuses on the college's role in professional examinations for trainee surgeons. Diversity among examiners is essential to ensure equitable outcomes for all groups, since success or failure in these examinations determines people's career trajectory. However, only $11 \%$ of current examiners are women (compared with $41 \%$ of female trainees in surgery), ${ }^{4}$ and only $30 \%$ are from ethnic minority backgrounds (compared with $46 \%$ of UK doctors who do not identify as white). ${ }^{5}$

Examiner roles are unpaid, and the selection process lacks transparency and is open to bias. Examiners are often encouraged to volunteer for these roles by peers, and there is no clear strategy to ensure equity in the process or diversity among appointees. This is particularly important, since men are twice as likely to pass college exams as women and ethnic minority candidates have a lower pass rate than those who identify as white. ${ }^{67}$ Again, surgery is not unique-a trained in the UK were also more likely to fail the clinical skills assessment component of the exam for membership of the Royal College of GPs (MRCGP). ${ }^{8}$

A major concern highlighted in the report is a lack of data collection on protected characteristics such as gender and sexual orientation. The report found little evidence on the experiences of LGBT+ surgeons or those with disabilities. Even so, "Over $70 \%$ of LGBT+ medics have endured one or more types of experiences short of harassment or abuse in the last two years related to their sexual orientation."1

One potential barrier to diversity in surgery is postgraduate recruitment to specialist surgical training. Recruitment is increasingly competitive, particularly for entry into higher surgical training, where the ratio of applicants to available posts increased from 2.16 in 2019 to 4.67 in $2020 .^{9}$

Diversity and inclusivity are stifled by a recruitment process that favours candidates with orthodox career paths and access to mentors and role models "like them." Minority trainees often lack mentors and role models and may be further disadvantaged by unavoidable periods outside formal training pathways that build clinical experience; paradoxically, points are taken away from candidates who are deemed to have "too much" clinical experience, weakening their application.

\section{Action not words}

The college president's decision to commission Kennedy's report shows a willingness to change. A report of this kind was long overdue, and many have welcomed its publication. It provides 16 recommendations in total (box 1), including committing the college: "To be an inclusive, diverse, professional organisation committed to fairness, and anti-discrimination, supporting and promoting the highest professional/surgical standards and the best outcomes for patients in a spirit of respect and compassion-for patients and for each other."

Box 1: Summary of Kennedy recommendations ${ }^{1}$

- Commit to the Royal College of Surgeons of England vision, putting diversity at the heart of college strategy

- Five recommendations urge reform of elections, including electoral conduct and processes, and appointments to key roles so that the leadership and study in 2013 showed that ethnic minority candidates 
council will reflect the diversity of the wider medical workforce within two electoral terms

- Develop a clear strategy for those in staff grade, associate specialist, and specialty doctor(SAS) positions, a reflection of the importance of the SAS community in surgery and "giving due recognition to the role of SAS practitioners"

- Establish a task force to work with deaneries, trusts, and hospitals to develop more supportive structures and career paths for trainees and surgeons who are parents

- Deliver a study on differential attainment in surgical exams, including a clear principled statement that the current differentials are not the function of learner deficit

- Launch two annual research fellowships in surgery, diversity, and inclusion

- Support diverse grassroots medical organisations with seed funding

- Improve data collection, monitoring, and career tracking so that progress can be measured on making opportunities available in a fair and inclusive way

Kennedy's report is a good start, but a profound change in culture is now required or the college risks being charged with empty virtue signalling. The recommendations must be implemented in full to avoid alienating a new generation of surgeons who do not belong to the traditional old boys' club and believe it should be dismantled. Lip service is no longer an option.

Competing interests: We have read and understood BMJ policy on declaration of interests and have no relevant interests to declare.

Provenance and peer review: Commissioned; not externally peer reviewed.

1 Royal College of Surgeons. We will put diversity at the heart of our strategy. 2021. https://www.rcseng.ac.uk/about-the-rcs/about-our-mission/diversity-review-2021/.

2 Rimmer A. "Old boys club" culture at BMA undermined female members and staff, sexism report finds. BMJ 2019;367:16089. doi: 10.1136/bmj.16089. pmid: 31624101

3 Romney D. Report into allegations of sexism and sexual harassment by members of the BMA's GP committee. 2019. https://www.bma.org.uk/media/1569/bma-daphne-romney-qc-report-oct19.pdf

4 Moberly T. A fifth of surgeons in England are female. BMJ 2018;363:k4530. doi: 10.1136/bmj.k4530. pmid: 30377150

5 UK Government. NHS workforce: ethnicity facts and figures. https://www.ethnicity-facts-figures.service.gov.uk/workforce-and-business/workforce-diversity/nhs-workforce/latest\#by-ethnicity-andtype-of-role

6 Scrimgeour DSG, Cleland J, Lee AJ, Brennan PA. Prediction of success at UK specialty board examinations using the mandatory postgraduate UK surgical examination. BJS Open 2019;3:865-71. doi: 10.1002/bjs5.50212. pmid: 31832594

7 BMA. BMA commentary on Mend the Gap: the independent review into gender pay gaps in medicine in England. 2020. https://www.bma.org.uk/media/3617/bma-commentary-on-medicinegender-pay-gap-dec-2020.pdf

8 Esmail A, Roberts C. Academic performance of ethnic minority candidates and discrimination in the MRCGP examinations between 2010 and 2012: analysis of data. BMJ 2013;347:f5662. doi: 10.1136/bmj.f5662. pmid: 24072882

9 Health Education England. Specialty training competition ratios. 2020. https://specialtytraining.hee.nhs.uk/Competition-Ratios. 